\title{
Long-term results of breast conservation and immediate volume replacement with myocutaneous latissimus dorsi flap
}

\author{
Fernando Hernanz ${ }^{1,3 *}$, Sonia Sánchez ${ }^{1,2}$, María Pérez Cerdeira ${ }^{3}$ and Carlos Redondo Figuero ${ }^{4}$
}

\begin{abstract}
Background: Published long-term outcomes of oncoplastic breast-conserving surgery are scarce and, specifically, aesthetic outcomes assessed with an objective method have not previously been published.

Methods: A cohort of 41 patients treated with a quadrantectomny and immediate reconstruction using a myocutaneous latissimus dorsi flap were analyzed and their aesthetic outcomes were evaluated objectively by BCCT.core software.

Results: At the end of a 58-month follow-up from the date of initial diagnosis, one patient (2.4\%) developed an ipsilateral recurrence, six patients developed distant metastases and three patients died (7.3\%) without ipsilateral recurrence, one of them presenting hepatic metastases at the time of the initial diagnosis. We were able to evaluate aesthetic results in 23 patients, 3 assessed as excellent, 12 good and 8 fair.

Conclusion: This oncoplastic volume replacement technique obtained a good local control and satisfactory and stable aesthetic results which have maintained unchanged after a long period of time.
\end{abstract}

Keywords: Oncoplastic breast surgery, long-term outcomes, cosmetic outcome and latissimus dorsi flap

\section{Background}

Oncoplastic breast-conserving surgery (OBS) has become a gold standard in the surgical treatment of early breast cancer increasing the rate of breast conserving treatment $(\mathrm{BCT})$, avoiding mastectomies and cosmetic sequelaes, and improving patients' quality of life and self-esteem.

Aesthetic outcome and degree of patient satisfaction is related to the percentage of breast tissue excised so when the preoperative estimation of this volume exceeds $20 \%$ of the total breast volume a reconstructive technique is required to obtain a good cosmetic outcome [1-3]. This option allows the achievement of the OBS goal: complete removal of the lesion, clear margins, the larger the better, good to excellent cosmetic result and operating once so as to perform the definitive procedure

\footnotetext{
* Correspondence: cgdhff@humv.es

"Breast Unit. Hospital, University of Cantabria, "Marqués de Valdecilla" (Avda Valdecilla s/n), Santander, (39008), Cantabria, Spain

Full list of author information is available at the end of the article
}

avoiding a complicated breast reconstruction postmastectomy process [4].

We published our experience using an OBS volume replacement technique (OVR), a real quadrantectomy and immediate reconstruction with myocutaneous latissimus dorsi flap (LDF) in one-stage procedure, analyzing the early results. The technique showed its utility allowing extensive resection, extending BCT to tumors with a mild response or no response after neoadjuvant chemotherapy, achieving good cosmetic outcomes and, in short, it could be particularly useful when radiotherapy indication, in the event of a mastectomy, were present before surgery or likely after surgery based on pathological features, such as more than three involved lymph nodes or bad prognostic factors [5-7]. Our experience with this technique obtained good early cosmetic results showing that symmetry and the quality of the reconstructed breast scar were the most influential factors in determining the cosmetic result [6].

The lack of randomized trial data makes comparison of OBS techniques difficult; most studies involve small 
cohorts of patients assessed for outcome in various ways and as far as aesthetic results are concerned, these are heterogeneous and difficult to evaluate in a standardized way [8]. A computer system (BCCT.core) has been developed to objectively and automatically evaluate the aesthetic result of BCT and it is has been proposed as a gold standard method for assessment of breast cosmesis in clinical trials as standard [9].

Some factors can deteriorate the early aesthetic outcome: the effect of radiotherapy reducing breast size and increasing the fibrotic, changes in body weight, and aging and gradual breast ptosis, which would worsen the cosmetic result increasing breast asymmetry. This has been experienced by Gendy, who observed an increment of the cosmetic failure rate from 10 to $18 \%$, in a period of 43 months, in patients treated with a partial mastectomy with latissimus dorsi miniflap reconstruction [10].

This article aims to evaluate the long-term results, oncologic and aesthetic, of a cohort of patients treated with an OVR and observe the effect of time on the cosmetic results.

\section{Methods}

We reviewed the records and radiological images of 41 patients treated with partial mastectomy (quadrantectomy or sector mastectomy) and immediate breast reconstruction by LDF (one-stage procedure) from November 2002 to May 2010; the patients' characteristics are described in table 1.

We calculated the estimated breast volume $\left(\mathrm{V}_{\mathrm{br}}\right)$ of 33 patients based on mammogram measurements using a modification of the Katariya method [11] assuming the elliptical cone projection with the formula:

$$
\mathrm{V}_{\mathrm{br}}=1 / 3 \mathrm{pi} \mathrm{R}_{\mathrm{cc}} \mathrm{R}_{\mathrm{ol}} \mathrm{H}_{\mathrm{ol}}
$$

where $\left(\mathrm{H}_{\mathrm{ol}}\right)$ height and $\left(\mathrm{R}_{\mathrm{ol}}\right)$ radius measurements were taken from oblique mammogram projection and $\mathrm{R}_{\mathrm{cc}}$ radius from craneocaudal projection.

Tumor size was defined as the largest dimension recorded on mammogram or magnetic resonance imaging (MRI); in those patients who were treated preoperatively with chemotherapy this measurement was taken from the MRI or mammogram once the treatment was finished or interrupted. The estimated volume of resection $\left(\mathrm{V}_{\text {ers }}\right)$ was determined assuming that theoretical resection is a sphere containing the tumor in its core surrounded by $1 \mathrm{~cm}$ of healthy breast tissue (margin):

$$
\mathrm{V}_{\mathrm{ers}}=4 / 3 \mathrm{pi} \mathrm{R}^{3}
$$

where $\mathrm{R}$ is equal tumor size $/ 2+1 \mathrm{~cm}$.

All the patients underwent oncologic and reconstructive procedures, carried out by a complete or comprehensive oncoplastic breast surgeon (HF). In one patient a reductive contralateral mammaplasty was performed concomitantly to obtain symmetry. Table 2 shows pathologic features; surgical specimen volume was calculated from specimen weight using the density of $0.958 \mathrm{~g} / \mathrm{cm}^{3}$. Positive margins were defined as having tumor cells right at the cut edge of the specimen. Close margins were defined as having tumor cells between the cut edge of the specimen and the boundary defined as negative $(>2 \mathrm{~mm})$. All the patients in this series received standard adjuvant radiotherapy, 50 Gy spread over four weeks, adjuvant systemic chemotherapy and endocrine therapy, which was indicated according to our standard protocol based on clinical and pathological findings.

Minimum follow-up was 13 months with an average of 58 from the date of initial pathological diagnosis until the date of the last study follow-up. All patients were followed-up clinically every 6 months for the first 3 years and then every year thereafter. Complete clinical examination, bilateral mammograms, chest X-rays, abdomino-pelvic ultrasonography and tumor markers were performed in each revision. Bone scans were indicated only in the event of suspicious blood tests or clinical symptoms.

The end point analyzed was the status (alive or dead, cause of death, free of disease or with recurrence, type of recurrence and survival) at the date of the last followup study.

\section{Assessment of cosmetic outcome}

Cosmetic outcome was evaluated by BCCT.core software. Standardized digital front photographs were taken of naked patients standing up straight with their arms down beside the body after an average of 55 months from the date of the end of radiotherapy. BCCT.core (breast cancer conservative treatment cosmetic results) software was developed by The University of Porto to evaluate cosmetic results of BCT in an objective standardized semiautomatic way, and divides the result into four categories (excellent, good, fair and bad) [9].

Patients were also asked about changes in the sensitivity of the nipple of the affected breast, chronic back pain or functional limitations of the shoulder during their domestic activities.

\section{Statistical analysis}

We calculated confidence intervals $(\mathrm{CI})$ of proportion by means of the Wilson method [12]. We study the correlation between $V_{\text {ers }}$ and the actual volume excised. Values of $\mathrm{p}<0.05$ were considered significant.

\section{Results}

Median follow-up was 58 months (13-95) and only two patients were lost at 16 and 64 months into the follow- 
Table 1 Characteristics of 41 patients.

\begin{tabular}{|c|c|c|}
\hline Characteristic & Value & IC-95\% \\
\hline \multicolumn{3}{|l|}{ Age (years) } \\
\hline Median (SD) & $44(7.5)$ & 41.7 to 46.3 \\
\hline Range & $22-58$ & \\
\hline \multicolumn{3}{|l|}{ Breast volume ${ }^{a}$ (cc) } \\
\hline Median (SD) & $705.4(294.0)$ & 605.1 to 805.7 \\
\hline \multicolumn{3}{|l|}{ Patient with breast volume n, (\%) } \\
\hline$<500$ & $8(24.2)$ & 12.8 to 41.0 \\
\hline $500-1000$ & $22(66.7))$ & 49.6 to 80.2 \\
\hline$<1000$ & $3(9.1)$ & 3.1 to 23.6 \\
\hline NC & 8 & \\
\hline \multicolumn{3}{|l|}{ Size of tumor* $(\mathrm{mm})$} \\
\hline Median (SD) & $22(11.25)$ & 18.4 to 25.6 \\
\hline Range & $0-45$ & \\
\hline \multicolumn{3}{|c|}{ Estimated volume of resection ${ }^{\circ}$ (cc) } \\
\hline Median (SD) & $47(36.33)$ & 35.3 to 58.7 \\
\hline \multicolumn{3}{|c|}{ Percentage of total breast volume } \\
\hline Median (SD) & $8.5(7.66)$ & 5.8 to 11.3 \\
\hline \multicolumn{3}{|l|}{ Patients n, (percentage) } \\
\hline $0-10 \%$ & $21(70)$ & 52.1 to 83.3 \\
\hline $10-20 \%$ & $5(16.7)$ & 7.3 to 33.6 \\
\hline$>20 \%$ & $4(13.3)$ & 5.3 to 29.7 \\
\hline $\mathrm{NC}$ & 11 & \\
\hline \multicolumn{3}{|c|}{ Distribution of tumor through the breast (no. patients) } \\
\hline Upper outer quadrant & 19 & \\
\hline Inferior inner quadrant & 1 & \\
\hline Inferior outer quadrant & 3 & \\
\hline Intersection upper quadrants & 9 & \\
\hline Intersection inferior quadrants & 2 & \\
\hline Intersection outer quadrants & 4 & \\
\hline Intersection inner quadrants & 3 & \\
\hline \multicolumn{3}{|l|}{ Multifocal } \\
\hline Yes & $8(19.5)$ & 10.2 to 34.0 \\
\hline No & $33(80.5)$ & 66.0 to 89.8 \\
\hline \multicolumn{3}{|c|}{ Histologic subtype of invasive carcinoma (no. of patients) } \\
\hline Ductal & 27 & \\
\hline Lobular & 10 & \\
\hline Solid & 1 & \\
\hline Apocrine & 1 & \\
\hline Phyllodes & 1 & \\
\hline Mixed & 1 & \\
\hline
\end{tabular}

a Volume of the breast was calculated using the formula $1 / 3$ pi $H R_{c c} R_{o l}$, $(H)$ height and $\left(R_{o l}\right)$ radius measurements were taken from oblique mammogram projection and $\mathrm{R}_{\mathrm{cc}}$ radius from craneocaudal one.

* Tumor size was defined as the largest dimension recorded on mammogram or magnetic resonance imaging (MRI); in 19 patients who were treated preoperatively with chemotherapy this measurement was taken from the MRI or mammogram once the treatment was finished or interrupted.

${ }^{\circ}$ Estimated volume of resection was determined using the formula $4 / 3 \mathrm{pi}$ (tumor size $\left./ 2+1\right)^{3}$.

SD: standard deviation, $\mathrm{Cl}$ : Confidence interval, NC: not confirmed

up. One patient developed an ipsilateral breast cancer recurrence $(2.4 \%)$, whose histological type was in situ ductal carcinoma, diagnosed 32 months after the date of the histological diagnosis. There were several factors that could have influenced this oncologic outcome, such as her young age (she was 44 years old), premenopausal status, the specific characteristics of her tumor: negative estrogen and progesterone receptors, positive Herb-2, 
Table 2 Characteristics of the surgical specimen (breast tissue and axillary lymph nodes)

\begin{tabular}{|c|c|c|}
\hline Characteristic & Value & IC $95 \%$ \\
\hline \multicolumn{3}{|l|}{ Weight, g } \\
\hline Median (SD) & $174.8(70.9)$ & 152.5 to 197.0 \\
\hline Range & $42-381$ & \\
\hline \multicolumn{3}{|l|}{ Volume $^{a}$ (cc) } \\
\hline Median (SD) & $167.4(67.9)$ & 146.1 to 188.7 \\
\hline Range & $40-364$ & \\
\hline \multicolumn{3}{|l|}{ Percentage of total breast volume } \\
\hline Median (SD) & $24.7(8.7)$ & 21.6 to 27.8 \\
\hline \multicolumn{3}{|l|}{ Patients (IC) } \\
\hline $0-10$ & 0 & 0.0 to 11.0 \\
\hline $10-20 \%$ & $12(38.7)$ & 23.7 to 56.2 \\
\hline$>20 \%$ & $19(61.3)$ & 43.8 to 76.3 \\
\hline NC & 10 & \\
\hline \multicolumn{3}{|l|}{ Margin, patients (percentage) } \\
\hline Involved, tumors cells & 0 & 17.6 to 44.5 \\
\hline Close,$<2 \mathrm{~mm}$ & $12(29.3)$ & 55.5 to 82.4 \\
\hline Negative, no tumors cells & $29(70.7)$ & \\
\hline \multicolumn{3}{|l|}{ Minimal width of margin, $\mathrm{mm}$} \\
\hline Median (SD) & $5.2(4.4)$ & 3.8 to 6.6 \\
\hline \multicolumn{3}{|l|}{ Axillary lymph nodes } \\
\hline Number of patients with positive lymph nodes, $\mathrm{n}$ (percentage) & $20(52.6)$ & 37.3 to 67.5 \\
\hline Number of patients with $>3$ positive lymph nodes $n$ (percentage) & $9(23.7)$ & 13.0 to 39.2 \\
\hline \multicolumn{3}{|l|}{ Positive hormone receptors, $\mathrm{n}$ (percentage) } \\
\hline Estrogenic & 19 & 19.6 to 47.0 \\
\hline Progesterone & 22 & \\
\hline Herb-2 & 11 & \\
\hline Triple-negative, $\mathrm{n}$ (percentage) & $13(31.7)$ & \\
\hline
\end{tabular}

NC: not confirmed, Cl: Confidence interval

and close margin caused by bifocal residual disease after neoadjuvant chemotherapy with a microfoci separated from the main tumor. She underwent a skin-sparing mastectomy and immediate breast reconstruction with an adjustable breast implant and she is alive and free of disease after 63 months' follow-up. (Figure 1)

Six patients developed distant metastases (14.63\%), at an average time of 30 months (19-46) after the date of histological diagnosis, the metastases sites were: bone, lung, liver and lymph nodes, and three patients died (7.3\%) due to the tumor without ipsilateral recurrence, one of them presenting hepatic metastases at the time of treatment. One patient developed a gastric cancer and another was diagnosed with contralateral breast cancer.

We were able to interview and evaluate 23 patients cosmetically, the reasons for this being: three patients died, one had an ipsilateral recurrence and was mastectomized, three had a distant recurrence and were in a bad state, one was diagnosed and treated for contralateral breast cancer and one had a surgical procedure on the affected breast, while the rest refused to participate

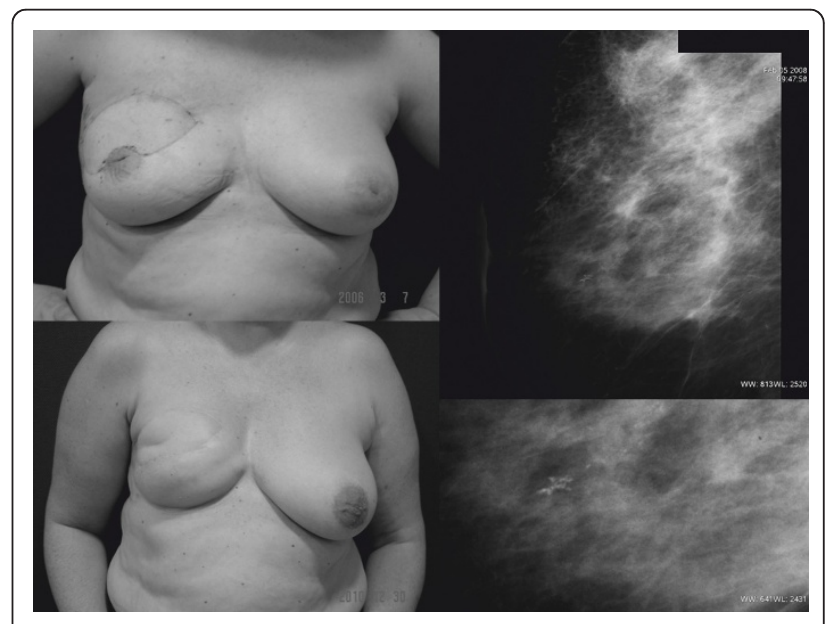

Figure 1 Appearance of the patient who suffered from an ipsilateral breast cancer recurrence, she underwent a skinsparing mastectomy and immediate breast reconstruction with an adjustable breast implant. She did not want undergo a reduction mammaplasty for simmetrization. Mammography showed a small group of microcalcifications; the core biopsy confirmed an in situ ductal carcinoma. 
or were impossible to contact. Table 3 shows cosmetic evaluation results and the changes from the previous evaluation [6,7]. In 19 patients we observed the evolution of the cosmetic outcomes, which had previously been assessed subjectively by a mixed panel in 2005 or 2007; four of them (21.05\%) have changed their assessment deteriorating from good to fair.

No patients expressed functional limitation in activities of daily life and, it is worth commenting that three women regularly go swimming, two or three times a week. One expressed a decrease in nipple sensation and another had chronic back pain.

\section{Discussion}

Breast surgery and, in particular, OBS should be an individual process for each patient; the appropriate surgical technique requires that the surgeon should choose between the different options, weighing up the pros and cons of each one. Multiple reconstructive techniques are available for partial breast reconstruction, the dominant criterion used for selection is the location of the tumor but factors such as breast size, degree of ptosis and density of the breast tissue should be taken into account [13]. The patient's condition and preferences, characteristics of the tumor [14], for example, associated component in situ, lobular histologic type, and the level of the surgeon's expertise in OBS training also determine the choice $[15,16]$.

Reviewing articles about OBS, more specifically those published in the last years, it can be observed that displacement techniques are more frequently used than volume replacement ones $[17,18]$, one explanation might be that some surgeons are reluctant to spend a distant flap, such as LDF, for a partial breast reconstruction, concerned that this could potentially compromise a reconstructive option in situations in which completion mastectomy is required. They prefer other options like skin sparing mastectomy with immediate reconstruction in those patients with small or medium breast size where tumor excision causes large defects and reshaping is not possible.

However, we consider that OVR are very useful when the indication of radiotherapy postmastectomy is sure or quite likely; in this situation, this option offers more advantages than the skin sparing mastectomy with immediate reconstruction. The procedure only requires one surgical intervention, which takes less time, does

Table 3 Aesthetic results.

\begin{tabular}{lccccc}
\hline Method of Evaluation & EXCELLENT & GOOD & FAIR & BAD & total \\
\hline Panel, 2005 & $2(6.8)$ & $15(51.7)$ & $11(37.9)$ & $1(3.4)$ & 29 \\
\hline BCCT.core, 2010 & $3(13.0)$ & $12(52.2)$ & $8(34.8)$ & 0 & 23 \\
\hline $\mathbf{n}$ (percentage) & & & & &
\end{tabular}

not need surgery on the contralateral breast and the patients conserve their own nipples without changes in sensation. In our series almost half of the patients had had radiotherapy indication if a mastectomy was carried out based on the initial size of the tumor or on the lymph node status.

Although new OVR techniques based on artery perforator flaps [19] as thoracodorsal flaps [20] have gained acceptance in the reconstruction options because they could replace the classic LDF not sacrificing this muscle and avoiding common donor site morbidity and postoperative seroma, the LDF remains as preferential option in some clinical situations as central or medial defects in patients with small or moderate size breast (bra cup size A,B,C) [21,22].

Outcomes of OBS are scarce and much more if we are dealing with OVR. In 2007 and 2008 Asgeirsson KS and Rainsbury $[17,18]$ published a review of seven series with a total of 189 patients with a follow-up of 24 to 53 months showing a low local recurrence rate (0 to $5 \%$ ) and cosmetic failure rate ( 0 to $18 \%$ ); our work obtained similar rates which fall into the range of this series but adds some more information about one OVR, the partial mastectomy with immediate LDF reconstruction, the usefulness in all quadrants of the breast achieving acceptable and stable aesthetic outcomes over a long period of time (Figure 2).

Our series can be characterized with some data: patients below the average age of breast cancer (44 years) with medium size breasts (705 cc average of total breast volume) suffered from tumors with $22 \mathrm{~mm}$ of average size (22 after neoadjuvant chemotherapy) located in all quadrants of the breast, multifocal in $20 \%$ cases, with high rate of axillary lymph node affectation (46.3\%) and triple-negative receptors (31.7\%). The OVR

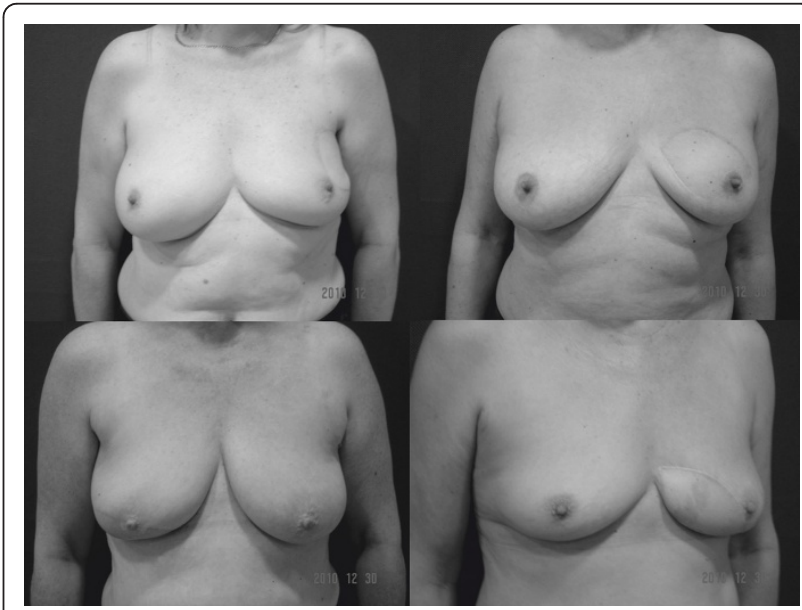

Figure 2 Long-term aesthetic results of OVR used in the four quadrants of the breast. 
used achieved appropriate margins (no patients had involved ones) and a good local control (rate of ipsilaterall recurrence of $2.4 \%$ ) but significant discordance between the estimated volume of resection $(6.6 \%$ of the breast volume) and the actual volume excised (24.7\%) was observed (correlation coefficient, $\mathrm{r}=0.0195, \mathrm{p}=$ 0.321). The explanation for this is the surgical specimen, a quadrantectomy or sector partial mastectomy, which does not fit a sphere containing the tumor in the core so some healthy breast tissue is unnecessarily taken out. Despite the high breast volume excised, with an average of $167 \mathrm{cc}$, which is similar to other published data (23, $24)$, the cosmetic results were not negatively affected.

Cosmetic outcome in OBS evaluated with an objective method have not been published previously. Aesthetic outcomes evaluated by BCCT.core are worse than when they are evaluated by a panel [25], but this is an objective and easily reproducible method which offers us the opportunity to standardize the evaluation allowing a fair comparison between different studies.

Cosmetically satisfactory results were achieved in $65 \%$ of cases after a long follow-up period 54 months (range from 5 to 92), similar results have been published by other authors such as Naguib SF [26], who published 69\% in a series of 29 patients, in which LDF was used in 21 cases, and 16 kept their NAP after a follow-up ranging from 3 to 36 months and Tomita K [27], who achieved 75\% good cosmetic results in 44 patients evaluated by a mixed panel one year after the end of treatment.

In 19 patients we observed the evolution of the cosmetic outcomes because they were assessed subjectively by a mixed panel in 2005 or 2007 . Only four patients have changed their assessment with deterioration from good to fair (Figure 3). The main reason that could

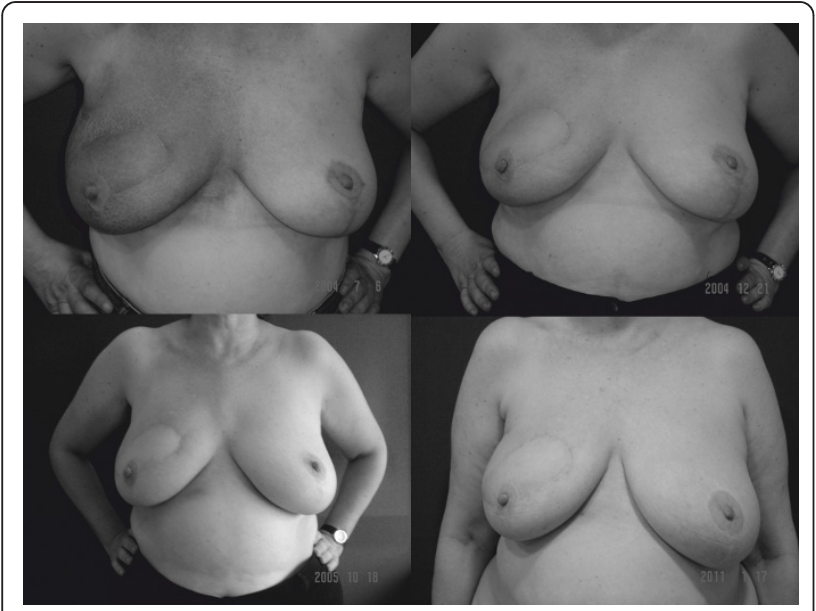

Figure 3 Appearance of the patient at different times, while the radiotherapy was delivered and, three months, two years and five years after the end of radiotherapy. explain this worsening is the increment of the asymmetry, which was together with the scar of the reconstructed breast the main factor determining the aesthetic result $[6,28]$. Like other breast surgeries (reconstruction, reduction and augmentation), changes in the weight status worsen the aesthetic results as we could see in three of the four patients whose aesthetic results worsened, two having put on weight and the other, who suffered from a second neoplasia, an advanced gastric carcinoma, losing weight dramatically.

Finally, we observed that the technique does not cause a late morbidity and the patients have a complete adjustment and do not have limitations in everyday life.

\section{Conclusion}

This OVR obtained a good local control and satisfactory and stable aesthetic results which have maintained unchanged after a long period of time. This option should be considered when the postmastectomy radiotherapy indication is present or likely

List of abbreviations used

OBS: Oncoplastic breast surgery; BCT: Breast conserving treatment; OVR: OBS volume replacement technique; LDF: Myocutaneous latissimus dorsi flap; MRI: Magnetic resonance imaging; Cl: Confidence intervals.

\section{Author details}

"Breast Unit. Hospital, University of Cantabria, "Marqués de Valdecilla" (Avda Valdecilla s/n), Santander, (39008), Cantabria, Spain. ${ }^{2}$ Department of Radiology. University of Cantabria, "Marqués de Valdecilla" (Avda Valdecilla s/ n), Santander, (39008), Cantabria, Spain. ${ }^{3}$ Department of Surgery. University of Cantabria, "Marqués de Valdecilla" (Avda Valdecilla s/n), Santander, (39008), Cantabria, Spain. ${ }^{4}$ Faculty of Medicine, University of Cantabria, Avda Cardenal Herrera Oria s/n, Santander,(39011), Cantabria, Spain.

\section{Authors' contributions}

$H F$, general surgeon who carried out the surgical procedures and principal investigator, participated in design and coordination of the study

SS, radiologist who participated in data collecting and reviewed radiological images

P-CM, general surgeon who participated in data collecting and surgical procedures

R-FC, physician and statistic who conducted statistical analysis

All authors read and approved the final manuscript

\section{Competing interests}

The authors declare that they have no competing interests.

Received: 31 August 2011 Accepted: 5 December 2011

Published: 5 December 2011

\section{References}

1. Bulstrode NW, Shrotria S: Prediction of cosmetic outcome following conservative breast surgery using breast volume measurements. Breast 2001, 10:124-126.

2. Cochrane RA, Valasiadou P, Wilson ARM, AI-Ghazal SK, Mcamillan RD: Cosmetic and satisfaction after breast conserving surgery correlates with the percentage of the breast volume excised. Br J Surg 2003, 90:1505-1509.

3. Chan SW, Cheung PS, Lam SH: Cosmetic outcome and percentage of breast volume excision in oncoplastic breast conserving surgery. World J surg 2010, 34:1447-1452. 
4. Silverstein MJ: How I do it: Oncoplastic breast-conservation surgery. Ann Surg Oncol 2010, 17(suppl 3):242-244.

5. Hernanz F, Alvarez A, Ortega E, Garijo F: Malignant cystosarcoma phyllodes of the breast treated with oncoplastic conservative surgery. Breast J 2005, 11:146.

6. Hernanz F, Regaño S, Redondo-Figuero C, Orallo V, Erasun F, GómezFleitas M: Oncoplastic breast-conserving surgery: analysis of quadrantectomy and immediate reconstruction with latissimus dorsi flap. World J Surg 2007, 31:1934-1940.

7. Regaño S, Hernanz F, Ortega E, Redondo-Figuero C, Gómez-Fleitas M: Oncoplastic techniques extend breast-conserving surgery to patients with neoadjuvant chemotherapy response unfit for conventional techniques. World J Surg 2009, 33:2082-2086.

8. Potter S, Harcourt D, Cawthorn S, Warr R, Mills N, Havercroft D, Blazeby J: Assessment of cosmesis after breast reconstruction surgery: a systematic review. Ann Surg Oncol 2011, 18:813-823.

9. Cardoso MJ, Cardoso J, Amaral N, Azevedo I, Barreau L, Bernardo M, Christie D, Costa S, Fitzal F, Fougo JL, Johansen J, Macmillan D, Mano MP, Regolo L, Rosa J, Texeira L, Vrieling C: Turning subjective into objective: the BCCT.core software for evaluation of cosmetic results in breast cancer conservative treatment. Breast 2007, 16:456-461.

10. Gendy RK, Able JA, Rainsbury RM: Impact of skin-sparing mastectomy with immediate reconstruction and breast-sparing reconstruction with miniflaps on the outcomes of oncoplastic breast surgery. Br J Surg 2003, 90:433-439.

11. Fung JYK, Chan SWW, Chiu ANK, Cheung PSY, Lam SH: Mammographic determination of breast volume by elliptical cone estimation. World Surg 2010, 34:1442-1445.

12. Wilson EB: Probable inference, the law of succession, and statistical inference. J Am Statist 1927, 22:209-212.

13. Clough KB, Kaufman GJ, Nos C, Buccimazza I, Sarfati IM: Improving breast cancer surgery: a classification and quadrant per quadrant atlas for oncoplastic surgery. Ann Surg Oncol 2010, 17:1375-1391.

14. Newman LA, Buzdar AU, Singletary SE, Kuerer HM, Buchholz T, Ames FC, Ross MI, Hunt KK: A prospective trial of preoperative chemotherapy in resectable breast cancer predictors of breast conservation therapy feasibility. Ann Surg Oncol 2002, 9:228-234.

15. de Andrade Urban C: New classification for oncoplastic procedures in surgical practice. Breast 2008, 17:321-322.

16. Rainsbury RM, Paramanathan N: UK survey of partial mastectomy and reconstruction. Breast 2007, 16:637-645.

17. Rainsbury RM: Surgery insight: Oncoplastic breast-conserving reconstruction-indications, benefits, choices and outcomes. Nat Clin Pract Oncol 2007, 4:657-664.

18. Asseirsson KS, Rasheed T, McCulley SJ, Macmillan RD: Oncological and cosmetic outcomes of oncoplastic breast conserving surgery. EJSO 2005, 31:817-823.

19. Levine JL, Soueid NE, Allen RJ: Algorithm for autologous breast reconstruction for partial mastectomy defects. Plast Reconstr Surg 2005, 116:762-767.

20. Hamdi M, Van Landuyt K, Hijjawi JB, Roche N, Blondeel P, Monstrey S: Surgical technique in pedicled thoracodorsal artery perforators flaps: a clinical experience with 99 patients. Plast Reconstr Surg 2008, 121:1632-1641.

21. Kronowitz SJ, Kuerer HM, Buchhloz TA, Valero V, Hunt KK: A management algorithm and practical oncoplastic surgical techniques for repairing partial mastectomy defects. Plast Reconstr Surg 2008, 122:1631-1647.

22. Munhoz AM, Montag E, Arruda E, Pellarin L, Filassi JR, Piato JR, de Barros AC, Prado LC, Fonseca A, Baracat E, Ferreira MC: Assessment of immediate conservative breast surgery reconstruction: a classification system of defects revisited and an algorithm for selecting the appropriate technique. Plast Reconstr Surg 2008, 121:716-727.

23. Kaur N, Petit JY, Rietjens M, Maffini F, Luini A, Gatti G, Rey PC, Urban C, de Lorenzi F: Comparative study of surgical margins in oncoplastic surgery and quadrantectomy in breast cancer. Ann Surg Oncol 2005, 12:539-545.

24. Giacalone P-L, Roger P, Dubon O, El Gareh N, Rihaoui S, Taourel P, Daurés JP: Comparative study of the accuracy of breast resection in oncoplastic surgery and quadrantectomy in breast cancer. Ann Surg Oncol 2007, 14:605-614.
25. Heil J, Dahlkamp J, Golatta M, Rom J, Domschke C, Rauch G, Cardoso MJ, Sohn C: Aesthetic in breast conserving therapy: Do objectively measured results match patient' evaluations? Ann Surg Oncol 2010, 18:134-138.

26. Naguib SF: Oncoplastic resection of retroareolar breast cancer: central quadrantectomy and reconstruction by local skin-glandular flap. J Egypt Natl Canc Ins 2006, 18:334-347.

27. Tomita K, Yano K, Matsuda K, Takada A, Hosokawa K: Esthetic outcome of immediate reconstruction with latissimus dorsi flap after breastconservative surgery and skin-sparing mastectomy. Ann Plast Surg 2008, 61:19-23.

28. Kim S, Lee S, Lee $H$, Lee J: The safety and cosmetic effect of immediate latissimus dorsi flap reconstruction after breast conserving surgery. $J$ Breast Canc 2009, 12:186-192.

doi:10.1186/1477-7819-9-159

Cite this article as: Hernanz et al:: Long-term results of breast conservation and immediate volume replacement with myocutaneous latissimus dorsi flap. World Journal of Surgical Oncology 2011 9:159.

\section{Submit your next manuscript to BioMed Central and take full advantage of:}

- Convenient online submission

- Thorough peer review

- No space constraints or color figure charges

- Immediate publication on acceptance

- Inclusion in PubMed, CAS, Scopus and Google Scholar

- Research which is freely available for redistribution

Submit your manuscript at www.biomedcentral.com/submit
Biomed Central 